\title{
Disponibilidade de ferro in vitro de grãos de soja tostados por diferentes tratamentos
}

\author{
Iron availability in vitro of soybean grains toasted by different treatments
}

Mônica Alves FELIX ${ }^{1}$, Solange Guidolin CANNIATTI-BRAZACA ${ }^{2 *}$

\section{Resumo}

A disponibilidade de alguns minerais, como o ferro, é alterada pela utilização de tratamentos pelo calor. Este trabalho teve por objetivo avaliar a disponibilidade de ferro in vitro e a composição centesimal de grãos de soja tostados por diferentes tratamentos. Realizaram-se cinco tratamentos, sendo dois com secagem prévia e três sem secagem prévia. O controle foi seco em estufa. Os teores de umidade, extrato etéreo, cinzas, fibra alimentar e carboidratos das amostras estudadas diferiram significativamente ( $\mathrm{p} \leq 0,05)$, enquanto que os teores de proteína não apresentaram diferenças estatísticas. A quantidade de ferro nas amostras analisadas variou de 83,67 a 58,8 mg.kg-1 e a porcentagem de ferro dialisado foi de 0,95 a 1,38\%. Conclui-se que a composição esteve dentro dos valores esperados para grãos de soja e que a tostagem foi responsável pela melhora na diálise de ferro in vitro.

Palavras-chave: soja; tostagem; disponibilidade; ferro; composição.

\begin{abstract}
The availability of some minerals, such as iron can be affected by heat. The aim of this research was the evaluation of the iron amount and availability in vitro and the centesimal composition in soybean grains roasted by different treatments. Five treatments had been done; two of them with previous drying and three without. The control was dried in a drier. The contents of humidity, ash, lipids, dietary fiber, and carbohydrates differ according to the treatments, but the protein contents did not vary statistically. The iron amount in the analyzed samples varied from 58.8 to $83.67 \mathrm{mg} . \mathrm{kg}^{-1}$ and the percentage of dialysed iron was from 0.95 to $1.38 \%$. It can be concluded that the proximal composition was within the expected values and that the roasting was responsible for the improvement of the availability of the iron in vitro.

Keywords: soybean; roasting; dialyse; iron; centesimal composition.
\end{abstract}

\section{Introdução}

Vários estudos têm demonstrado que o consumo de grãos ou subprodutos da soja está freqüentemente associado com a redução do risco de inúmeras doenças, tais como câncer de esôfago, pulmão, próstata, mama e cólon/reto, doenças cardiovasculares, osteoporose, diabetes e sintomas da menopausa (CHUNG et al., 1996; CLARK et al., 1996; GALLAGHER et al., 2000).

Estudos sobre as características nutricionais e nutracêuticas da soja têm promovido o seu consumo via incorporação da soja na dieta alimentar da população brasileira. Para tanto, a demanda mundial por soja e subprodutos está em franco crescimento. Entre os fatores, está não somente o aumento do consumo na alimentação humana, mas também o aumento da produção animal no mundo, principalmente de ciclo curto como suínos e aves, em virtude do banimento, na Europa, das farinhas de origem animal (CHIARELLO, 2002).

Em geral, os grãos de leguminosas são ricos em proteínas, carboidratos, vitaminas (especialmente do complexo B) e minerais, mas também apresentam alguns componentes antinutricionais, os quais se ligam às proteínas e alguns minerais como, por exemplo, o ferro, inibindo sua absorção e a biodis- ponibilidade (DISLER et al., 1975; LINDER, 1988; HALLBERG et al., 1992).

A soja tostada também possui elevado teor de ferro, 3,9 mg. $100 \mathrm{~g} \mathrm{~g}^{-1}$, em comparação com o teor encontrado em feijões cozidos, que variam de 0,9 a $2,5 \mathrm{mg} \cdot 100 \mathrm{~g}^{-1}$ (USDA, 2005).

Entretanto, a quantidade total de ferro de um alimento ou dieta não indica a quantidade que estará biodisponível, porque existem vários fatores que influenciam a absorção e utilização desse mineral. Dessa forma, para garantir suporte adequado de ferro, é necessário conhecer e diferenciar a quantidade total de ferro da quantidade biodisponível. A quantidade de ferro biodisponível está relacionada à medida da fração de ferro alimentar capaz de ser absorvida pelo trato gastrointestinal e, subseqüentemente, armazenada e incorporada ao ferro heme (FAIRWEATHER-TAIT et al., 1995).

A deficiência de ferro é o problema nutricional de maior prevalência mundial, ocorrendo tanto nos países desenvolvidos como nos países em desenvolvimento. A anemia ferropriva tem como causa a ingestão insuficiente, perda excessiva ou absorção inadequada de ferro (HAMBRAEUS, 1999).

Recebido para publicação em 24/4/2007

Aceito para publicação em 9/3/2008 (002483)

${ }^{1}$ Laboratório de Bromatologia, Departamento de Agroindústria, Alimentos e Nutrição, Escola Superior de Agricultura Luiz de Queiroz - ESALQ,

Universidade de São Paulo - USP, Av. Pádua Dias, 11, CP 9, CEP 13418-900, Piracicaba - SP, Brasil, E-mail: mfelix@esalq.usp.br

2 Departamento de Agroindústria, Alimentos e Nutrição, Escola Superior de Agricultura Luiz de Queiroz-ESALQ, Universidade de São Paulo - USP, Av. Pádua Dias, 11, CP 9, CEP 13418-900, Piracicaba - SP, Brasil, E-mail: sgcbraza@esalq.usp.br

${ }^{*}$ A quem a correspondência deve ser enviada 
Os grupos populacionais mais afetados pela anemia por deficiência de ferro, em ordem de prioridade, são: mulheres grávidas e lactantes, crianças ( $0-2$ anos), crianças pré-escolares (2-6 anos), mulheres não grávidas em idade fértil, idosos, adolescentes e homens adultos. Mais de dois bilhões de pessoas, ou seja, 1/3 da população mundial é anêmica devido a várias causas, incluindo a deficiência de ferro, que é a causa subjacente em cerca de um bilhão de casos de anemia. Em adição, outro um bilhão de pessoas têm estoque subnormal de ferro, ou seja, possuem deficiência de ferro sem, porém, serem consideradas clinicamente anêmicas (UNICEF, 1998).

Devido aos efeitos deletérios que a deficiência de ferro tem sobre a saúde, e considerando o aumento no consumo da soja em grãos na alimentação humana, em virtude dos benefícios que esta pode promover à saúde, este trabalho teve por objetivo verificar a concentração e a dialisibilidade do ferro em grãos de soja tostados por diferentes tratamentos, além de sua composição centesimal.

\section{Material e métodos}

Como matéria-prima foram utilizados para a realização do experimento grãos de soja (Glycine max (L.) Merrill), cultivar BRS 133, safra 2002/2003, cultivada na Estação Experimental de Anhembi - ESALQ/USP.

Para as análises, os grãos de soja crus foram lavados, macerados e submetidos a diferentes tratamentos, tendo como controle a amostra macerada e seca.

Foram realizados os seguintes tratamentos:

- T1 - Tratamento 1: maceração do grão em água deionizada na proporção 1:3 (14 horas), descarte da água, retirada manual da casca, secagem em estufa por 8 horas $\left(55^{\circ} \mathrm{C}\right)$, tostagem em forno a gás por 10 minutos à temperatura de $220^{\circ} \mathrm{C}$;

- T2 - Tratamento 2: maceração do grão em água deionizada na proporção 1:3 (14 horas), descarte da água, retirada manual da casca, secagem em estufa por 8 horas $\left(55^{\circ} \mathrm{C}\right)$, tostagem em forno a gás por 15 minutos à temperatura de $220^{\circ} \mathrm{C}$;

- T3 - Tratamento 3: maceração do grão em água deionizada na proporção 1:3 (14 horas), descarte da água, retirada manual da casca, tostagem em forno a gás por 45 minutos à temperatura de $220^{\circ} \mathrm{C}$;

- T4 - Tratamento 4: maceração do grão em água deionizada na proporção 1:3 (14 horas), descarte da água, retirada manual da casca, tostagem em forno a gás por 50 minutos à temperatura de $220^{\circ} \mathrm{C}$;

- T5 - Tratamento 5: maceração do grão em água deionizada na proporção 1:3 (14 horas), descarte da água, retirada manual da casca, tostagem em forno a gás por 60 minutos à temperatura de $220^{\circ} \mathrm{C}$; e

- Controle: maceração do grão em água deionizada na proporção 1:3 (14 horas), descarte da água, retirada manual da casca e secagem em estufa por 31 horas a $55^{\circ} \mathrm{C}$.
Os grãos secos e tostados no laboratório foram triturados em moinho de facas e a farinha peneirada em malha de 30 "mesh", a qual foi utilizada para as análises químicas. Essa farinha foi armazenada em saco de polietileno fechado e mantida em temperatura de refrigeração $\left(4^{\circ} \mathrm{C}\right)$. Todas as análises foram realizadas em triplicata.

As análises químicas de teor de umidade, cinzas, proteína bruta, extrato etéreo e fibra alimentar total foram realizadas de acordo com a metodologia indicada pela AOAC (2006).

Os carboidratos foram obtidos por diferença, ou seja, 100\% ( $\%$ proteína $+\%$ umidade $+\%$ fibra alimentar total $+\%$ cinzas $+\%$ extrato etéreo).

O teor de ferro foi determinado pelo método descrito por Sarruge e Haag (1974), sendo utilizada a digestão úmida com ácido nítrico e perclórico.

Realizou-se a diálise de ferro segundo o método proposto por Luten et al. (1996). A soja foi submetida à digestão in vitro. A diálise foi realizada colocando-se o digerido em sacos de diálise. Adicionou-se solução de bile pancreatina. Ao sobrenadante adicionou-se solução cromogênica. A quantidade de ferro dialisado foi obtida através da utilização de uma curva padrão previamente preparada.

O delineamento estatístico foi inteiramente casualizado. Realizou-se análise de variância pelo teste $F$ e comparação das médias obtidas nos diferentes tratamentos segundo teste de Tukey $(\mathrm{p}<0,05)$ (PIMENTEL-GOMES, 1982) através do programa Statistical Analysis System (1996). Para melhor comprovação dos resultados, foi realizado o desdobramento dos graus de liberdade de tratamentos em contrastes ortogonais, como segue:

- $\mathrm{Y} 1 \rightarrow$ todos versus controle $=\mathrm{T} 1+\mathrm{T} 2+\mathrm{T} 3+\mathrm{T} 4+\mathrm{T} 5-$ $5 \mathrm{~T} 6$

- $\mathrm{Y} 2 \rightarrow$ com secagem versus sem secagem $=3 \mathrm{~T} 1+3 \mathrm{~T} 2-$ $2 \mathrm{~T} 3-2 \mathrm{~T} 4-2 \mathrm{~T} 5+0 \mathrm{~T} 6$;

- Y3 $\rightarrow$ forno por 10 minutos versus forno por 15 minutos, com secagem $=\mathrm{T} 1-\mathrm{T} 2+0 \mathrm{~T} 3+0 \mathrm{~T} 4+0 \mathrm{~T} 5-0 \mathrm{~T} 6$;

- Y4 $\rightarrow$ forno por 45 minutos + forno por 50 minutos versus forno por 60 minutos, sem secagem $=0 \mathrm{~T} 1+0 \mathrm{~T} 2+\mathrm{T} 3+$ T4 - 2T5 - 0T6; e

- Y5 $\rightarrow$ forno por 45 minutos versus forno por 50 minutos, sem secagem $=0 \mathrm{~T} 1+0 \mathrm{~T} 2+\mathrm{T} 3-\mathrm{T} 4-0 \mathrm{~T} 5-0 \mathrm{~T} 6$.

\section{Resultados e discussão}

Os dados referentes à composição centesimal dos grãos de soja tostados por diferentes tempos encontram-se na Tabela 1 .

Como podem ser observados, os teores de umidade, extrato etéreo, cinzas, fibras alimentares totais e carboidratos das amostras estudadas diferiram significativamente $(p \leq 0,05)$, enquanto que os teores de proteína não apresentaram diferenças estatísticas. 
Tabela 1. Médias obtidas pelos tratamentos e teste de Tukey para a composição centesimal de grãos de soja tostados por diferentes tempos.

\begin{tabular}{ccccccc}
\hline Tratamentos $^{3}$ & Umidade (\%) & Extrato etéreo (\%) & Proteína (\%) & Cinzas (\%) & Fibras totais (\%) & Carboidrato (\%) \\
\hline T1 & $8,33 \pm 0,4^{\text {la2 }}$ & $22,25 \pm 0,9^{\mathrm{c}}$ & $33,09 \pm 3,0^{\mathrm{a}}$ & $4,44 \pm 0,1^{\mathrm{b}}$ & $18,66 \pm 0,1^{\mathrm{cd}}$ & 13,23 \\
T2 & $7,57 \pm 0,4^{\mathrm{a}}$ & $22,74 \pm 0,4^{\mathrm{bc}}$ & $32,67 \pm 2,2^{\mathrm{a}}$ & $4,49 \pm 0,1^{\mathrm{b}}$ & $20,49 \pm 1,3^{\mathrm{b}}$ & 12,04 \\
T3 & $6,20 \pm 0,2^{\mathrm{b}}$ & $24,66 \pm 0,9^{\mathrm{a}}$ & $34,27 \pm 1,9^{\mathrm{a}}$ & $4,49 \pm 0,0^{\mathrm{b}}$ & $20,18 \pm 0,1^{\mathrm{bc}}$ & 10,20 \\
T4 & $7,27 \pm 0,5^{\mathrm{ab}}$ & $24,20 \pm 0,4^{\mathrm{ab}}$ & $32,99 \pm 1,5^{\mathrm{a}}$ & $4,53 \pm 0,1^{\mathrm{b}}$ & $21,75 \pm 0,6^{\mathrm{ab}}$ & 9,26 \\
T5 & $4,83 \pm 0,6^{\mathrm{c}}$ & $24,07 \pm 0,2^{\mathrm{ab}}$ & $34,64 \pm 0,7^{\mathrm{a}}$ & $4,54 \pm 0,1^{\mathrm{b}}$ & $22,66 \pm 0,6^{\mathrm{a}}$ & 9,26 \\
Controle & $1,97 \pm 0,1^{\mathrm{d}}$ & $24,11 \pm 0,3^{\mathrm{ab}}$ & $32,72 \pm 2,0^{\mathrm{a}}$ & $4,81 \pm 0,1^{\mathrm{a}}$ & $17,75 \pm 0,5^{\mathrm{d}}$ & 18,63 \\
\hline
\end{tabular}

${ }^{1}$ Média \pm desvio padrão; ${ }^{2}$ Médias seguidas de letras iguais, nas colunas, não diferem entre si pelo teste de Tukey a $5 \%$ de significância (p $\leq 0,05$ ); $\mathrm{e}^{3}$ Tratamentos: T1 - com pré-secagem + 10 minutos de forno; $\mathrm{T} 2$ - com pré-secagem + 15 minutos de forno; T3 - sem pré-secagem + 45 minutos de forno; T4 - sem pré-secagem + 50 minutos de forno; e T5 - sem présecagem +60 minutos de forno.

A porcentagem de umidade entre as amostras apresentou variação de 4,83 a $8,33 \%$. Os tratamentos com pré-secagem (T1 e T2) tiveram médias significativamente maiores $(\mathrm{p} \leq 0,05)$ que os sem secagem, exceto para o T4. Esse resultado pode ser explicado pelo fato de que as amostras relativas a esses tratamentos, apesar de terem sido previamente secas, ficaram expostas ao calor por um tempo bem menor que as demais. Tal fato é comprovado pelo resultado da $\mathrm{T} 1$, que obteve a maior média, mas ficou por menor tempo, 10 minutos. Nos tratamentos sem pré-secagem, as médias do T3 e T4 foram significativamente maiores $(\mathrm{p} \leq 0,05)$ que as médias do T5, novamente confirmando a influência do tempo de tostagem na umidade do grão. O controle apresentou média significativamente inferior $(\mathrm{p} \leq 0,05)$ aos demais tratamentos, sendo esse valor justificado pelo tempo de exposição à temperatura de estufa, ou seja, 31 horas a $55^{\circ} \mathrm{C}$.

Café et al. (2000) encontraram teor de umidade de 12,16\% para soja tostada, valor próximo ao encontrado por Monteiro et al. (2003) para farinha de soja integral, processada a $89{ }^{\circ} \mathrm{C}$ durante 5 minutos, da qual se obteve $12,81 \%$ de umidade.

A porcentagem de umidade referida pelo National Research Council (NRC) de 1977, 1988 e 1998 para soja tostada é de $10 \%$. A média de umidade encontrada por Murray (1996) em soja crua foi de $10,8 \%$, semelhante ao valor referido pelo NRC, apesar de se apresentar em condições de processamento bastante diferentes. Portanto, esse valor pode variar de acordo com o tratamento empregado, como ocorrido neste trabalho, cujos teores variaram de acordo com o tempo de tostagem aplicado.

Quanto aos valores obtidos para o extrato etéreo (Tabela 1), estes variaram de 22,25 a 24,74\%. A média de extrato etéreo encontrada por Café et al. (2000) na análise de soja tostada foi de $18,67 \%$. O NRC $(1977,1988$ e 1998$)$ apresentou para a soja tostada valores de extrato etéreo de 18,0, 18,8 e 18,0\%, respectivamente. Essa diferença pode ser devido à retirada da casca. Já Rodrigues et al. (2002) verificaram, na soja tostada, 22,06\% de lipídios, sendo esse valor bem próximo ao encontrado por Monteiro et al. (2003), que referem 23,74\% para farinha de soja integral. Como podem ser observados, os valores encontrados (Tabela 1) são bastante satisfatórios, pois encontram-se de acordo com a literatura.

O teor de proteínas encontrado variou de 32,67 a 34,64\% (Tabela 1), estando de acordo com a média encontrada por Café et al. (2000), que foi de 34,93\% para soja tostada. De acordo com Bressani e Elias (1974), o conteúdo de proteína de várias leguminosas varia de 18 a 32\%. Segundo o NRC (1977, 1988 e
1998), o teor de proteínas para soja tostada foi de 37, 36,7 e $35,2 \%$, respectivamente. Setna (2000) refere, para soja tostada, o teor de 36\%, confirmado por Blas, Mateos e Rebollar (2001). Rostagno (2000) encontrou 37,5\% para soja tostada, sendo que resultado semelhante foi verificado por Rodrigues et al. (2002). Considerando os valores referenciados, os teores obtidos (Tabela 2) ainda se encontram dentro dos limites esperados, sendo, portanto, considerados como adequados quanto ao tipo de processamento aplicado.

Os resultados das cinzas são condizentes com os apresentados por Café et al. (2000), que apresentaram teores de cinzas de $4,37 \%$ para a soja tostada. Valores semelhantes foram encontrados por Rodrigues et al. (2002) na análise de soja tostada, sendo estes, em média, de 4,46\%. Segundo Bressani e Elias (1974), o conteúdo de cinzas em leguminosas varia de 2,5 a $4,2 \%$ na matéria seca.

Quanto ao teor de fibras totais, os valores encontrados estão entre 17,75 e $22,66 \%$, havendo equivalência com os dados da Tabela de Composição dos Alimentos da Faculdade de Ciências Farmacêuticas (2005), que apresenta a quantidade de $21,67 \%$ para grãos de soja crus. Já Kawaga (1995) apresenta o teor de $17,1 \%$ de fibras totais para grãos crus. Observando os valores encontrados, verifica-se que, em comparação à literatura citada, a tostagem em forno convencional não alterou os teores de fibras.

As quantidades de carboidratos disponíveis, obtidos por diferença, nas amostras analisadas apresentaram valores que variaram de 9,26 a 18,63\%. A maior média foi obtida pelo controle $(18,63 \%)$, devido às características da composição dessa amostra, principalmente com relação à umidade.

Segundo Rodrigues et al. (2002), a quantidade de carboidratos encontrada em soja integral tostada foi de $10,16 \%$. Monteiro et al. (2003) descreveram valor médio de 17,36\% de carboidratos para a farinha de soja integral. De acordo com a FAO (2005), a quantidade de carboidratos na soja crua é de $15,8 \%$, estando de acordo com os dados apresentados na Tabela 1.

Os resultados obtidos na análise do ferro em base fresca e sua disponibilidade estão apresentados na Tabela 2 .

De acordo com a Tabela 2, a quantidade de ferro nas amostras analisadas variou de 83,67 a $58,8 \mathrm{mg} \cdot \mathrm{kg}^{-1}$. Verifica-se que, com base no teste de Tukey, para ferro em base fresca não houve diferença $(p>0,05)$ entre os tratamentos. 
Elpo, Freitas e Gomes (1998) avaliaram o teor de ferro de alguns alimentos da cesta básica do Estado do Paraná e encontraram valores de 59,84 a 78,75 mg. $\mathrm{kg}^{-1}$ de ferro para o feijão. Esses dados demonstram que os valores encontrados neste trabalho são bastante satisfatórios, porém, impedem maiores considerações e analogias, contudo, a comparação foi realizada em virtude de ambas serem leguminosas.

A Tabela 3 apresenta os resultados dos contrastes ortogonais referentes aos diferentes tratamentos empregados nos grãos em relação ao teor de ferro e a disponibilidade.

Segundo Canniatti-Brazaca e Silva (2003), há variação no teor de ferro das leguminosas que vai de 68,33 (feijão guandu) a $153,4 \mathrm{mg} . \mathrm{kg}^{-1}$ (soja). Neste caso, verifica-se que os valores encontrados estão abaixo dos citados pelos referidos autores, no entanto, essa variação pode ser decorrente de diferenças no clima, condições de solo, maturidade, variedades, além de fatores de processamento (BATH et al., 1999).

Entretanto, Cook (1983) e Lynch (1997) confirmam que não é o maior teor de ferro total o responsável pela maior absorção deste mineral. Neste caso, é possível observar que entre as amostras com pré-secagem (Tabela 2), a T2 foi a que apresentou, em termos absolutos, o menor teor total de ferro, mas, em contrapartida, a maior disponibilidade do mesmo. Entre as amostras que não receberam pré-secagem, o T3 segue a mesma

Tabela 2. Médias obtidas pelos tratamentos e teste de Tukey, para as variáveis referentes à porcentagem de ferro em base fresca e disponível.

\begin{tabular}{ccc}
\hline Tratamentos $^{3}$ & Ferro em base fresca $\left(\mathrm{mg} \cdot \mathrm{kg}^{-1}\right)$ & Ferro disponível (\%) \\
\hline T1 & $83,67 \pm 12,1^{\mathrm{1a} 2}$ & $0,95 \pm 0,0^{\mathrm{b}}$ \\
T2 & $65,77 \pm 6,2^{\mathrm{a}}$ & $1,27 \pm 0,0^{\mathrm{ab}}$ \\
T3 & $61,53 \pm 4,6^{\mathrm{a}}$ & $1,38 \pm 0,1^{\mathrm{a}}$ \\
T4 & $74,40 \pm 17,2^{\mathrm{a}}$ & $1,25 \pm 0,0^{\mathrm{ab}}$ \\
T5 & $63,27 \pm 0,7^{\mathrm{a}}$ & $1,19 \pm 0,3^{\mathrm{ab}}$ \\
Controle & $58,80 \pm 2,8^{\mathrm{a}}$ & $1,22 \pm 0,1^{\mathrm{ab}}$ \\
\hline
\end{tabular}

${ }^{1}$ Média \pm desvio padrão; ${ }^{2}$ Médias seguidas de letras iguais, nas colunas, não diferem entre si pelo teste de Tukey, a $5 \%$ de significância $(\mathrm{p} \leq 0,05) ;{ }^{3}$ Tratamentos: T1 - com pré-secagem +10 minutos de forno; 2 - com pré-secagem +15 minutos de forno; T3 - sem pré-secagem +45 minutos de forno; T4 - sem pré-secagem +50 minutos de forno; e T5 - sem pré-secagem + 60 minutos de forno. regra. O controle foi o que obteve o menor valor quanto ao teor de ferro total, porém, a disponibilidade foi semelhante ao T2, T4 e T5, sendo que o T4 foi a amostra que obteve o segundo maior valor de ferro total de todos os tratamentos. Esses resultados confirmam que o ferro total não guarda relação direta com o ferro disponível.

Krachler e Rossipal (2000) constataram, in vivo, que o mecanismo envolvido possivelmente esteja ligado à saturação dos receptores para absorção do ferro. Assim, à medida que todos os receptores já estão ligados ao mineral, o aumento de ferro total só daria proporcionalmente menor valor de ferro absorvido. Dessa forma, é provável a existência de relação ótima entre ferro total e ferro absorvido.

A análise do ferro indica o teor do mineral presente na amostra, porém não indica quanto deste ferro será realmente absorvido. Sabe-se que nem todo ferro presente no alimento é absorvido, podendo ser total ou parcialmente utilizado pelo indivíduo. Segundo Monsen et al. (1978), a absorção de ferro pode variar de 2 a 35\% em refeições, dependendo da presença de substâncias inibidoras ou estimuladoras. No caso da soja tostada, este valor foi menor do que a faixa de variação sugerida por esses autores (Tabela 2).

Encontrou-se porcentagem de ferro disponível que variou de 0,95 a 1,38\% (Tabela 2), sendo que a maior média obtida foi para o T3, estatisticamente diferente $(\mathrm{p} \leq 0,05)$ apenas do T1, pois os demais tratamentos não diferiram nem do $\mathrm{T} 3$, nem do T1.

Martini (2002) verificou que a quantidade de ferro disponível para o feijão comum (Phaseolus vulgaris), após cocção a $121{ }^{\circ} \mathrm{C}$ por 10 minutos, foi de $0,81 \%$. Assim, com base nesta referência, observa-se que todos os valores encontrados nas amostras analisadas ficaram acima do encontrado para o feijão comum.

Este resultado pode ser decorrente da desnaturação da proteína, visto que esse efeito pode aumentar a disponibilidade devido à hidrólise dos resíduos de aminoácidos das proteínas da soja submetida ao aquecimento. A hidrólise em partes menores também torna as cadeias protéicas mais susceptíveis às enzimas proteolíticas e causam liberações mais rápidas de produtos de

Tabela 3. Valor dos contrastes ortogonais e respectiva significância estatística pelo teste $F$.

\begin{tabular}{|c|c|c|}
\hline \multicolumn{3}{|l|}{ Ferro em base fresca $\left(\mathrm{mg} \cdot \mathrm{kg}^{-1}\right)$} \\
\hline Critérios & Coeficiente de correlação & $\mathrm{p}$ \\
\hline $\mathrm{Y} 1=$ todos versus controle & $+54,64$ & 0,08281 \\
\hline $\mathrm{Y} 2=$ com secagem versus sem secagem & $+49,92$ & 0,10988 \\
\hline $\mathrm{Y} 3=$ forno por 10 minutos versus forno por 15 minutos, com secagem & $+17,90$ & $0,03333^{*}$ \\
\hline $\mathrm{Y} 4=$ forno por 45 minutos + forno por 50 minutos versus forno por 60 minutos, sem secagem & $+9,39$ & 0,50915 \\
\hline $\mathrm{Y} 5$ = forno por 45 minutos versus forno por 50 minutos, sem secagem & $-12,87$ & 0,11032 \\
\hline \multicolumn{3}{|l|}{$\begin{array}{ll} & \text { Ferro disponível (\%) } \\
\end{array}$} \\
\hline $\mathrm{Y} 1=$ todos versus controle & $-0,06$ & 0,82306 \\
\hline $\mathrm{Y} 2=$ com secagem versus sem secagem & $-0,98$ & $0,04058^{\star}$ \\
\hline $\mathrm{Y} 3=$ forno por 10 minutos versus forno por 15 minutos, com secagem & $-0,32$ & $0,01409^{*}$ \\
\hline $\mathrm{Y} 4=$ forno por 45 minutos + forno por 50 minutos versus forno por 60 minutos, sem secagem & $+0,25$ & 0,21251 \\
\hline Y5 = forno por 45 minutos versus forno por 50 minutos, sem secagem & $+0,13$ & 0,27999 \\
\hline
\end{tabular}

\footnotetext{
${ }^{*}$ Valor significante a $5 \%(\mathrm{p} \leq 0,05)$ pelo teste $F$
} 
digestão, aminoácidos e peptídeos, que podem aumentar a disponibilidade por complexar o ferro com compostos de baixo peso molecular (KAPANIDIS; LEE, 1995).

Segundo Hurrell et al. (1989), existe relação direta entre o grau de hidrólise e o ferro dialisado.

Através da análise dos contrastes ortogonais dos diferentes tratamentos (Tabela 3), observa-se que o controle (Y1), do ferro em base fresca, não apresentou diferença significativa $(p>0,05)$ quanto aos demais tratamentos. Os tratamentos com secagem também não diferiram estatisticamente $(\mathrm{p}>0,05)$ dos sem secagem (Y2). Entretanto, nota-se que entre os tratamentos com secagem, o menor tempo foi o mais eficiente, pois as médias do $\mathrm{T} 1$ foram significativamente superiores $(\mathrm{p} \leq 0,05)$ às médias do T2 (Y3). A umidade parece ser fator importante, visto que, nos tratamentos sem secagem, não houve diferença entre as médias do T3 e T4 $(\mathrm{p}>0,05)$, as quais foram iguais às médias do T5 $(\mathrm{p}>0,05)(\mathrm{Y} 4)$.

Já com relação ao ferro dialisável (Tabela 3), o controle não diferiu $(p>0,05)$, em média, dos demais tratamentos, demonstrando que, neste caso, a temperatura de estufa parece ter influenciado positivamente para o desdobramento protéico (Y1). Entretanto, verifica-se que houve inversão de valores quanto à dialisibilidade em comparação com o ferro em base fresca, pois os tratamentos com secagem tiveram médias significativamente menores $(\mathrm{p} \leq 0,05)$ que os sem secagem $(\mathrm{Y} 2)$. Este resultado demonstra que pode ter ocorrido desnaturação protéica mais drástica nos que sofreram a pré-secagem, visto que entre os tratamentos sem secagem não houve diferença significativa $(\mathrm{p}>0,05)$.

Nos tratamentos com secagem, as médias do T1 foram significativamente menores $(\mathrm{p} \leq 0,05)$ que as médias do $\mathrm{T} 2$, ou seja, utilizando-se o contraste ortogonal (Y3), observa-se que o tempo de 10 minutos foi favorável quanto à concentração de ferro, mas não aumentou a disponibilidade do mesmo, necessitando, para tanto, de maior tempo de tostagem.

\section{Conclusões}

De acordo com os dados obtidos, concluiu-se que a tostagem em forno convencional, sem secagem prévia, foi mais eficiente para a melhora da disponibilidade do ferro. A composição centesimal esteve dentro dos valores esperados para este produto, alterando-se somente em relação à umidade.

\section{Agradecimentos}

À Fundação de Apoio à Pesquisa do Estado de São Paulo (FAPESP), ao Departamento de Genética da ESALQ/USP, pela doação das sementes e à Dra. Maria Isalina Ferreira Alves e à estagiária Viviane Aparecida Petruz, pelas análises estatísticas.

\section{Referências bibliográficas}

AOAC - Association of Official Analytical Chemists. Official methods of analysis. $20 \mathrm{ed}$. Arlington, 2006.

BATH, D. et al. Byproducts and unusual feedstuffs. Feedstuffs, v. 71, n. 31, p .32-38, 1999.
BLAS, C.; MATEOS, G. G.; REBOLLAR, P. G. (Eds). Normas FEDNA sobre valoración nutritiva de leguminosas y cereales tratados. Madrid: Universidad Politecnica de Madrid, 2001. 18 p.

BRESSANI, R.; ELIAS, L. G. Legume foods. In: ALTSCHUL, A. M. New protein foods. New York: Academic Press, 1974. p. 230-297.

CAFÉ, M. B. et al. Determinação do valor nutricional das sojas integrais processadas para aves. Revista Brasileira de Ciência Avícola, v. 2, n. 1, p. 1516-1535, 2000.

CANNIATTI-BRAZACA, S. G.; SILVA, F. C. Enhancers and inhibitors of iron availability in legumes. Plant Foods for Human Nutrition, v. 58, n. 3, p. 1-8, 2003.

CHIARELLO, M. D. A soja e os alimentos funcionais: oportunidades de parcerias em P\&D para os setores público e privado. Revista Parcerias Estratégicas, n. 15, p. 48-60, out. 2002.

CHUNG, T. K. H. et al. A randomized, double-blind, placebocontrolled, crossover study on the effect of oral estradiol on acute menopausal symptoms. Maturitas, v. 25, n. 2, p. 115-123, 1996.

CLARK, J. W. et al. Effects of tyrosine kinase inhibitors on the proliferation of human breast cancer cell lines and proteins important in the ras signaling pathway. International Journal of Cancer, v. 65, n. 2, p. 186-191, 1996.

COOK, J. D. Determinants of nonheme iron absorption in man. Food Technology, v. 37, n. 10, p. 124-126, 1983.

DISLER, P. B. et al. The effect of tea on iron absorption. Gut British Society of Gastroenterology, v. 16, n. 3, p. 193-200, 1975.

ELPO, E. R. S.; FREITAS, R. J. S.; GOMES, E. C. Avaliação dos teores de ferro nos alimentos da cesta básica. Archivos Latinoamericanos de Nutrición, v. 48, n. 1, p. 65-67, 1998.

FACULDADE DE CIÊNCIAS FARMACÊUTICAS. Tabela brasileira de composição de alimentos: projeto integrado de composição de alimentos. Disponível em: $<$ http://www.fcf.usp.br/tabela/tbcamenu. php>. Acesso em: 22 ago. 2005.

FAIRWEATHER-TAIT, S. J. et al. The bioavailability of iron in different weaning foods and the enhancing effects of a fruit drink containing ascorbic acid. Pediatric Research, v. 37, n. 4, p. 389-394, 1995.

FAO. Carbohydrates in human nutrition. Rome, 1998. 140 p. Disponível em: <www.fao.org/es/esn/nutrition/carboweb/carbo. pdf.> Acesso em: 22 ago. 2005.

GALLAGHER, J. C. et al. The effect of soy protein on bone metabolism. Journal of Nutrition, v. 130, n. 3, p. 667s, 2000. Oral Presentation Abstract. Session 2.

HALLBERG, L. et al. Calcium and iron absorption: mechanism of action and nutritional importance. European Journal of Clinical Nutrition, v. 46, n. 3, p. 317-327, 1992.

HAMBRAEUS, L. Animal and plant food based diets and iron status: benefits and costs. Proceedings of the Nutrition Society, v. 58, n. 2, p. 235-242, 1999.

HURRELL, R. F. et al. Iron absorption in human as influenced by bovine milk proteins. American Journal of Clinical Nutrition, v. 49, n. 3, p. 546-552, 1989.

KAGAWA, A. (Ed). Standard table of food composition in Japan. Tokyo: University of Nutrition for Women, 1995. p. 104-105.

KAPANIDIS, A. N.; LEE, T. C. Heating cruciferous vegetables increases in vitro dialyzability of intrinsic and extrinsic iron. Journal of Food Science, v. 60, n. 1, p. 128-131, jan./feb. 1995.

KRACHLER, M.; ROSSIPAL, E. Concentrations of trace elements in extensively hydrolysed infant formula and their estimated daily intakes. Annals of Nutrition and Metabolism, v. 44, n. 2, p. 68-74, 2000 . 
LINDER, M. C. Nutrición: aspectos bioquímicos, metabólicos y clínicos. Pamplona: Eunsa, 1988. p. 189-216.

LUTEN, J. et al. Interlaboratory trial on the determination of the in vitro iron dialysability from food. Journal of the Science of Food and Agriculture, v. 72, n. 4, p. 415-424, 1996.

LYNCH, S. R. Interaction of iron with otrher nutrientes. Nutrition Research, v. 55, n. 4, p. 102-110, 1997.

MARTINI, F. C. C. Comparação entre a disponibilidade de ferro na presença de vitamina $A$ e beta-caroteno em alimentos e medicamentos. Piracicaba, 2002. Dissertação - (Mestrado em Ciência e Tecnologia de Alimentos), Escola Superior de Agricultura "Luiz de Queiroz", Universidade de São Paulo.

MONSEN, E. R. et al. Estimation of available dietary iron. American Journal of Clinical Nutrition, v. 31, n. 1, p. 134-141, 1978.

MONTEIRO, M. R. P. et al. Avaliação da digestibilidade protéica de genótipos de soja com ausência e presença do inibidor de tripsina Kunitz e lipoxigenases. Brazilian Journal of Food Technology, v. 6, n. 1, p. 99-107, 2003.

MURRAY, J. H. The role of the micronizer in full fat soya production with reference to young animal nutrition. In: International Fullfat Soya Conference, 2, 1996, Budapest. Annals... Budapest, Hungria: American Soybean Association, 1996. p. 67-77.

NATIONAL RESEARCH COUNCIL. Nutrient requirements of pigs. 8 ed. Washington: National Academy of Science, 1977.
Nutrient requirements of pigs. 9 ed. Washington: National Academy of Science, 1988.

. Nutrient requirements of pigs. $10 \mathrm{ed}$. Washington: National Academy of Science, 1998.

PIMENTEL-GOMES, F. Curso de Estatística Experimental. 10 ed. São Paulo: Nobel, 1982. 430 p.

RODRIGUES, P. B. et al. Valores energéticos da soja e subprodutos da soja, determinados com frangos de corte e galos adultos. Revista Brasileira de Zootecnia, v. 31, n. 4, p. 1771-1782, 2002.

ROSTAGNO, H. S. Tabelas brasileiras para aves e suínos. Viçosa: Universidade Federal de Viçosa, 2000. 140 p.

SARRUGE, J. R.; HAAG, H. P. Análises químicas em plantas. Piracicaba: ESALQ, 1974. 56 p.

SETNA. Tablas de composición de materias primas. Madrid: Rivas Vaciamadrid, 2000. $30 \mathrm{p}$.

STATISTICAL ANALYSIS SYSTEM INSTITUTE. SAS/QC Software: usage and reference. 2 ed. NC: Cary, 1996. 2v. (version 6). CD-ROM.

UNICEF. Situação mundial da infância. Brasília, 1998. p. 92-97.

USDA - United States Department of Agriculture. Agricultural Research Service. Nutrient data laboratory. Disponível em: $<$ http:// www.nal.usda.gov>. Acesso em: 22 ago. 2005. 